\title{
Current correction and fuzzy logic optimizations of Perturb \& Observe MPPT technique in photovoltaic panel
}

\author{
Meriem Ourahou*, Wiam Ayrir, and Ali Haddi \\ Laboratory of Innovative Technologies, National School of Applied Sciences, Abdelmalek Essaâdi University, 93030 Tangier, \\ Morocco
}

Received: 29 December 2017 / Accepted: 17 February 2019

\begin{abstract}
This paper presents a two-way optimization of the Perturb \& Observe (P\&O) maximum power point tracking (MPPT) technique using current correction and fuzzy logic techniques. In fact, photovoltaic (PV) energy has become more and more coveted today. In the future, it will become a necessity. To ensure its optimization, maximum operating point tracking method is considered as a technological key in PV systems. One of the most used MPPT methods is the $\mathrm{P} \& \mathrm{O}$ technique. In this paper, we will focus on optimizing this method based on two techniques. A first attempt has been made to estimate a current correction of the $\mathrm{P} \& \mathrm{O}$ algorithm in case of illumination variation. Then, fuzzy logic optimization attempt had been highlighted to improve power loss. It is shown that both proposed techniques are very effective and allow considerable improvement of accuracy and are less affected by sudden variation of climatic parameters. The proposed approaches are tested via Matlab software and compared the classical P\&O algorithm. Through applications, we could conclude that the two optimized proposed methods offer a remarkable improvement concerning power losses.
\end{abstract}

Keywords: MPPT / Perturb \& Observe algorithm / Fuzzy logic / Current correction / Photovoltaic energy

\section{Introduction}

Faced with the depletion of fossil energy, solar energy provided by photovoltaic (PV) panels is an inexhaustible energy, reliable, easy to use, and especially respects nature and environment. Several researches have been developed since centuries through modeling techniques for renewable energy including PV systems. The aim is to develop opportunities for future investment and economic feasibility. Moreover, this energy remains the most "elegant" since it is silent and easily integrated into housing. However, PV energy production is nonlinear and varies depending on factors such as the illumination, the temperature, and the age of the panel itself. Therefore, operating point of the PV panel is often not coinciding with the maximum power point (MPP). So, the challenge is to, constantly, determine the maximum operating point of the $\mathrm{PV}$ panel in order to assign a maximum power to the load at all times. Indeed, the power generated by a PV panel depends on its operating voltage. Thus, the characteristic curves $V-I$ and $V-P$ specify a single point where the maximum power is delivered. This method is called maximum power point tracking (MPPT) [1,2].

\footnotetext{
* e-mail: meriem. ourahou@gmail.com
}

To increase the efficiency of this method, we insert a regulation system on the PV panel that makes it a "follower" and allows us to optimize the electricity production depending on the type of sensors used, speed, efficiency, price, and accuracy.

Because the illumination and temperature levels clearly influence the operation at maximum power of the PV panel, this was the starting point for various techniques of MPPT. In this paper, we focus on the "Perturb \& Observe" (P\&O) method. In fact, when irradiation changes rapidly, the MPP drifts since the load is changing after each perturbation, and therefore the $\mathrm{P} \& \mathrm{O}$ method used loses its effectiveness [3]. This constitutes a niche for the first optimization technique which will be developed in the present paper. Afterward, another technique for optimizing the $\mathrm{P} \& \mathrm{O}$ method based on fuzzy logic will be highlighted. The aim of this second technique is to make a correction of the classic P\&O method. Finally, a comparison between the two methods is made in order to determine which is the most effective.

The paper is organized as follows: Section 2 presents a mathematical model of a photovoltaic generator (PVG), Section 3 is devoted to the optimization techniques, Section 4 deals with the results and discussion, and Section 5 presents a summary of the results. 

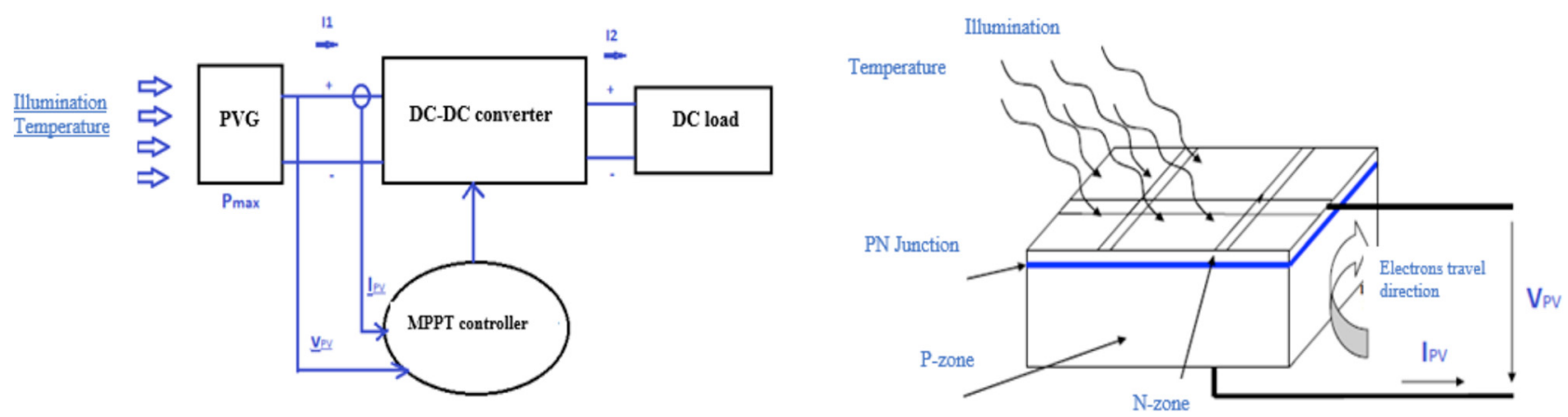

Fig. 1. Photovoltaic cell cross-section and conversion elementary chain controlled by an MPPT controller.

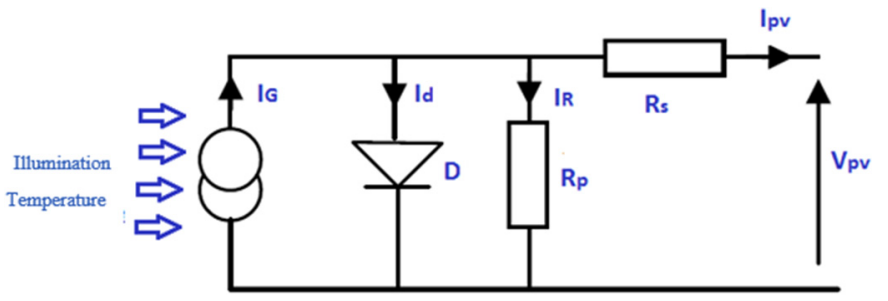

Fig. 2. Electrical model of photovoltaic cell.

\section{Photovoltaic generator mathematical model}

A PVG is composed of several PV cells mounted in series and/or in parallel. It is also composed of a conversion system (DC-DC converter), MPPT controller, and storage device (DC load). This set is called a PV system and is shown in Figure 1. In fact, $\mathrm{PV}$ panel is the result of conversion of energy that photons carry from light when they are in contact with suitably processed semiconductor materials. When the incident light communicates energy to the semiconductor's electrons, some of them exceed the potential barrier. They are thus expelled to an external circuit $[4,5]$.

Figure 2 shows the photovoltaic cell electrical model.

$$
I_{\mathrm{PV}}=I_{\mathrm{G}}-I_{\mathrm{R}}-I_{\mathrm{d}} \text {. }
$$

According to the Shockley equation: $I_{\mathrm{d}}=I_{0}\left(\exp \left(e . V_{\mathrm{d}} /\right.\right.$ K.T) -1 )

And: $V_{\mathrm{d}}=(K . T / e) \cdot \ln \left(I_{\mathrm{d}} / I_{0}+1\right)$.

Also, when the circuit to the terminals of the cell is opened: $V_{0 \mathrm{c}}=(K . T / e) \cdot \ln \left(I_{\mathrm{cc}} / I_{0}+1\right)$.

The parallel current which passes through the $R_{\mathrm{p}}$ resistance is: $I_{\mathrm{R}}=V_{\mathrm{d}} / R_{\mathrm{p}}$.

Taking into account the effect of the series resistance, we have: $V_{\mathrm{d}}=V+R_{\mathrm{s}}$.I.

The final equation of $\mathrm{PV}$ panel model is: $I=I_{\mathrm{cc}}-I_{0}(\exp$ $\left.\left(e .\left[V+R_{\mathrm{s}} \cdot I\right] / K . T\right)-1\right)-\left(\left[V+R_{\mathrm{s}} \cdot I\right] / R_{\mathrm{p}}\right)$.

Figure 3 explicates the characteristics of power-voltage $(P-V)$ and current-voltage $(I-V)$ of a $\mathrm{PV}$ panel using Simulink interface of Matlab software. This panel model is composed of 12 solar cells in series as shown in Table 1.
Table 1. PV panel characteristics.

\begin{tabular}{ll}
\hline Illumination & $1000 \mathrm{~W} / \mathrm{m}^{2}$ \\
\hline Temperature & $25^{\circ} \mathrm{C}$ \\
Short circuit current $\left(I_{\mathrm{cc}}\right)$ & $7.34 \mathrm{~A}$ \\
Short circuit voltage $\left(V_{0 \mathrm{c}}\right)$ & $0.6 \mathrm{~V}$ \\
Number of cells per module & 12 \\
\hline
\end{tabular}

The MPP differs depending on temperature and illumination [6-9]. Indeed, Figure 4 shows current curves variations for a steady temperature of $25^{\circ} \mathrm{C}$ and different illuminations of $1000 \mathrm{~W} / \mathrm{m}^{2}, 600 \mathrm{~W} / \mathrm{m}^{2}$, and $300 \mathrm{~W} / \mathrm{m}^{2}$. Also, once illumination remains steady at $1000 \mathrm{~W} / \mathrm{m}^{2}$ and temperature changes, from $300 \mathrm{~K}$ to $360 \mathrm{~K}$, MPP varies considerably.

Conversion system is based on a BOOST type DC-DC converter. Figure 5 shows the electrical structure of this converter. The purpose of this converter is to realize an adaptation lift source-load between input and output voltage $\left(V_{\mathrm{e}}\right.$ and $\left.V_{\mathrm{s}}\right)[10]$.

At time $t=0$, the transistor is closed. For a time $t$ between 0 and $\alpha T$, we have:

$$
V_{\mathrm{e}}=L \mathrm{~d} i / \mathrm{d} t
$$

So:

$$
i(t)=V_{\mathrm{e}} / L \cdot t+I_{1}
$$

The current curve is thus a growing curve based on the value $I_{1}$.

At the moment $\alpha T$, the transistor is opened. For a time $t$ between $\alpha T$ and period $T$, we have:

$$
V_{\mathrm{e}}-V_{\mathrm{s}}=L \mathrm{~d} i / \mathrm{d} t .
$$

So,

$$
i(t)=\left(V_{\mathrm{e}}-V_{\mathrm{s}}\right) / \text { L.t }+I_{2} .
$$

For the BOOST converter, $V_{\mathrm{s}}$ is always higher than $V_{\mathrm{e}}$. The power curve is decreasing starting from $I_{2}$ current value. Current curve during period $T$ is then shown in Figure 6 .

If the BOOST converter is in continuous conduction and its performance is ideal, we deduce that the adaptation 


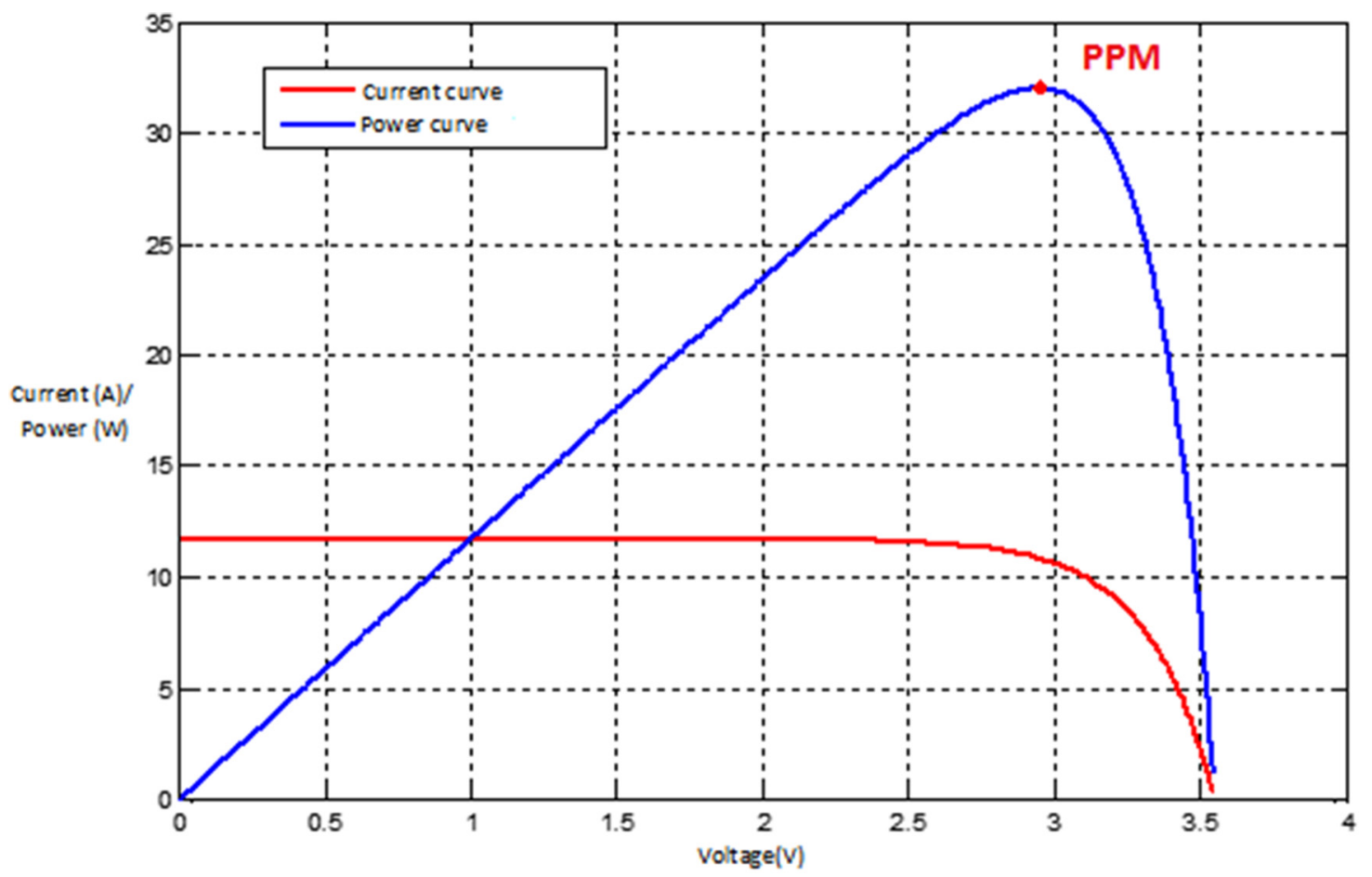

Fig. 3. Power-voltage $(P-V)$ and current-voltage $(I-V)$ characteristics.
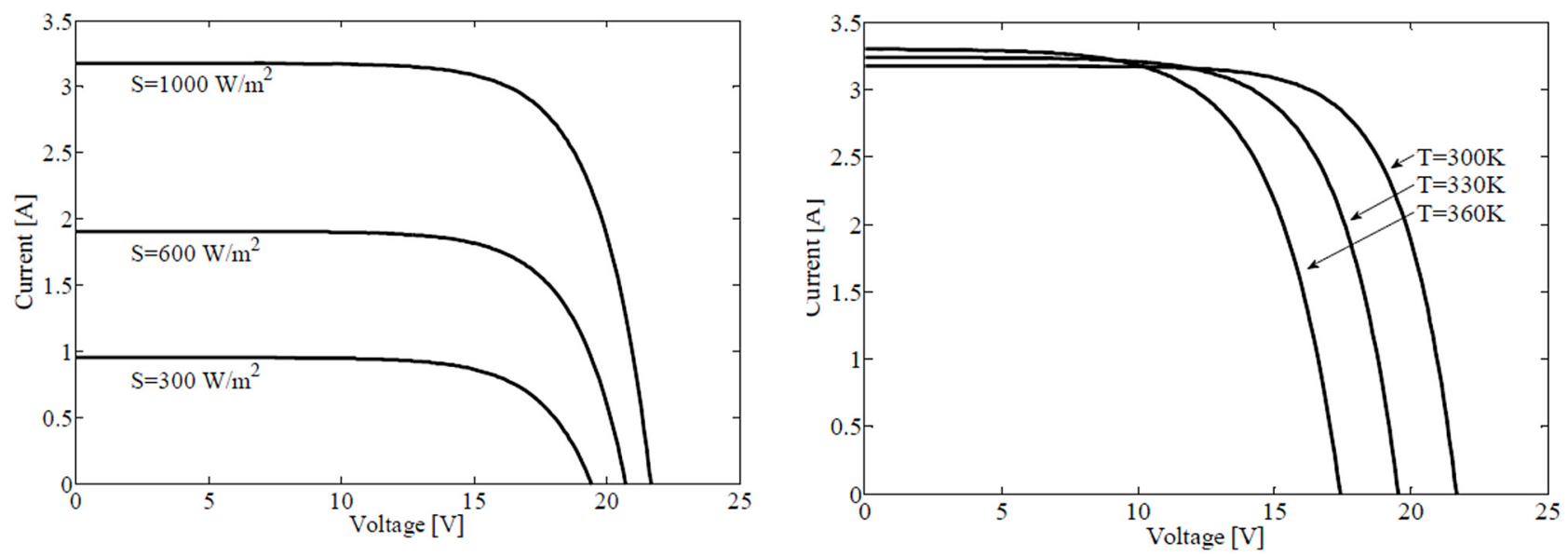

Fig. 4. $I-V$ photovoltaic panel characteristics under different climate conditions.

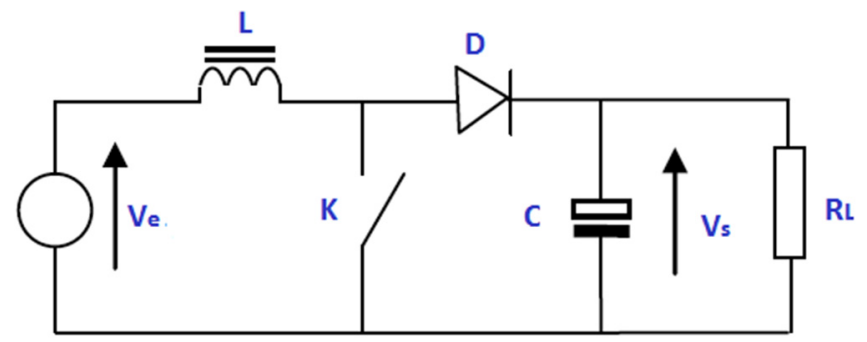

Fig. 5. Electrical structure of the BOOST converter. between the source and the load depends on the duty cycle. Indeed, the voltage $V_{\mathrm{s}}$ can be expressed according to the voltage $V$ :

$$
V_{\mathrm{s}}=V_{\mathrm{e}} /(1-\alpha) \text { and } I_{\mathrm{s}}=(1-\alpha) I_{\mathrm{e}}
$$

By varying the duty cycle $\alpha$, we can act on the load in such a way to maximize the power delivered by the PV panel. This is the main interest of the MPPT commands. 


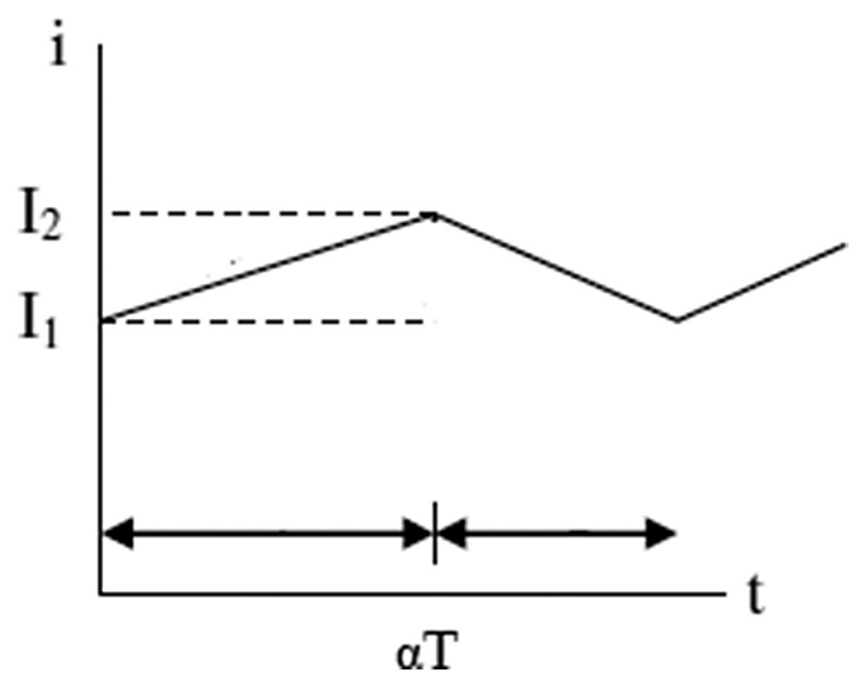

Fig. 6. Current curve for a BOOST converter.

\section{Optimization techniques}

\subsection{Perturb \& Observe method}

MPPT method is a mechanism that ensures instantaneous adaptation of the load operating point to the power supplied by the PVG. A distinction is made between direct and indirect research methods:

- Direct MPPTs operate through currents, voltages, or power measurements directly on the system. This ensures the reaction in case of unpredictable changes.

- Indirect MPPTs operate through the measured values and the approximate position of the MPP.

Among the MPPT commands, $\mathrm{P} \& \mathrm{O}$ is one of the most used commands because of its simple structure and the reduced number of parameters to control [11].

The principle is to generate disturbances by reducing or increasing the duty ratio $D$ and to observe the effect of the generated power by the PV panel. Once the periodic $V$ the voltage disturbance of the panel is done, it can decide on the next cycle [12-14]. It is also important to note that the disturbance $\Delta V$ is low so that the power variation is not too excessive. Thus, if:

$-\mathrm{d} P / \mathrm{d} V>0$, we approach the MPP and the perturbation moves the operating point closer to the MPP. The cyclic ratio variation in the same direction is thus maintained until the MPP has been reached.

$-\mathrm{d} P / \mathrm{d} V<0$, we move away from the MPP and the perturbation moves the operating point farther from the MPP. The cyclic ratio variation must be done in the opposite direction until reaching the MPP.

$-\mathrm{d} P / \mathrm{d} V=0$, we are at the MPP.

For this method there is a compromise between accuracy and speed since the disturbance must be very low so that the power change is not too big and thus minimize power losses $[15,16]$. The controller based on the $\mathrm{P} \& \mathrm{O}$ algorithm has two input values that are measured constantly, which are the current and the voltage. From

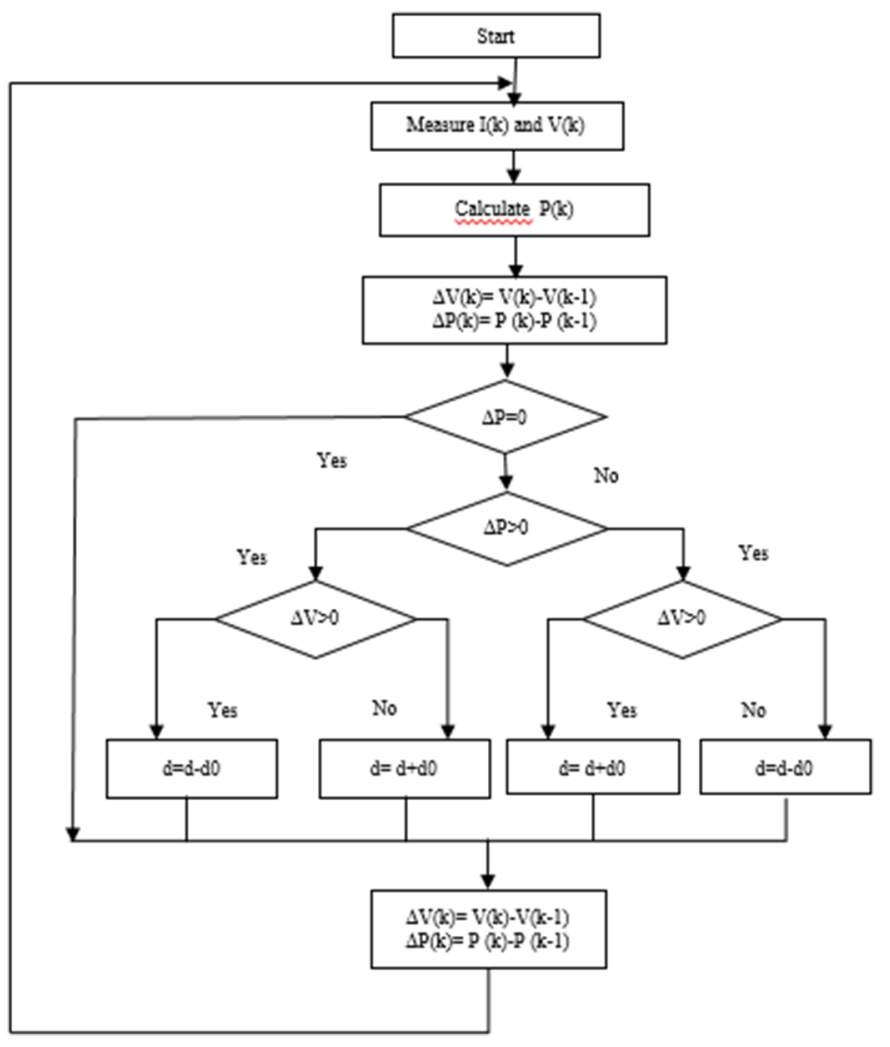

Fig. 7. Perturb \& Observe classic algorithm.

these measurements, it calculates the power $P$, the voltage variation $\Delta V$, and the power variation $\Delta P$ between $K$ and $K-1$ iterations as shown in Figure 7.

The output power of a PVG depends on the received irradiation. Indeed, the voltage does not vary considerably contrary to current that increases strongly.

In this case, the solution would be to make a control loop not only over voltage and power but also over the current. It allows to control permanently current variation and thus to identify as much as possible any variation of illumination. In fact, at each instant $k$, the $\mathrm{PV}$ panel has a characteristic $I-V$. These two parameters are measured continuously at the input of each cycle. Thus, instead of calculating only voltage and power variations $V$ and $P$, we also calculate the variation of the current $I$. This will reflect any eventual insolation variation at the cycle input. Where applicable, this will be a new characteristic $I-V$ of the PV panel. So, the algorithm can act directly on the duty cycle to correct this drift, to regain control of power and voltage, and therefore to go back to the classic maximum operating point tracking.

Indeed, in a classic $\mathrm{P} \& \mathrm{O}$ algorithm, the value of current $I$ measured at panel output is never stable and varies within a range of absolute value lower than a limit $L$ as [17]:

$$
I=i(k)-i(k-1) \text { and }|\Delta I|<L .
$$

In order to make the algorithm insensible to these current changes due to the oscillation, we will set a 


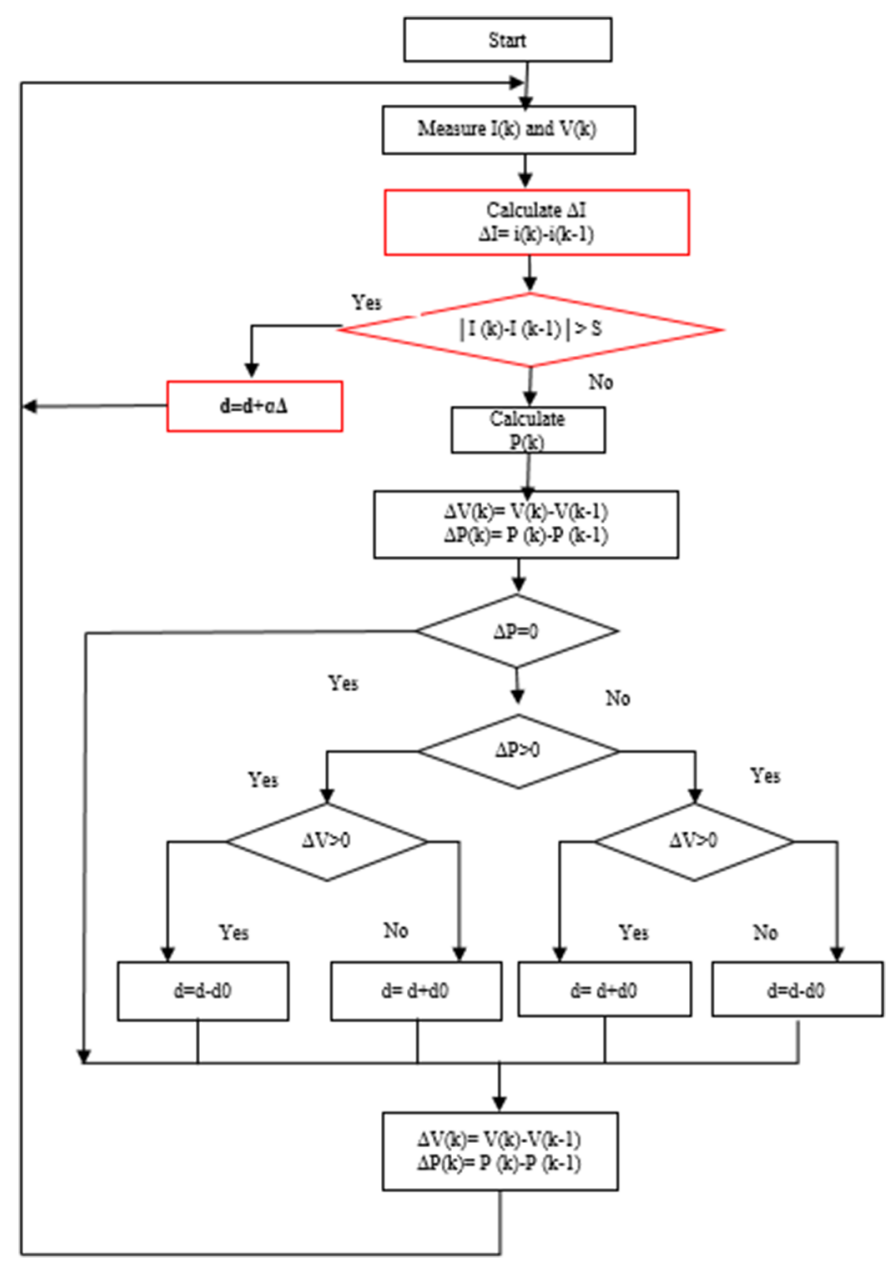

Fig. 8. Optimized Perturb \& Observe algorithm.

threshold $S$ higher than the limit $L$. It will allow to test insolation variation. Therefore, we take a value $S>L$. So if:

$-|i(k)-i(k-1)|<S$, the algorithm is a classic $\mathrm{P} \& \mathrm{O}$ algorithm that has not gone through any insolation variation.

- $|i(k)-i(k-1)|>S$, the PV panel has gone through an insolation variation. That gives a new characteristic curve $I-V$. And the algorithm acts directly on the cyclic ratio.

The operating direction depends on the sign of the current variation $I$. In fact, if:

$-I>0$, so the insolation variation has increased and the voltage must then be incremented by $V$.

$-I<0$, so the insolation variation has decreased and the voltage must be decremented by $V$.

Figure 8 presents the proposed optimized P\&O algorithm with current correction.

\subsection{Fuzzy logic method}

The world that surrounds the human being is full of uncertainties and inaccurate perceptions. By nature, man

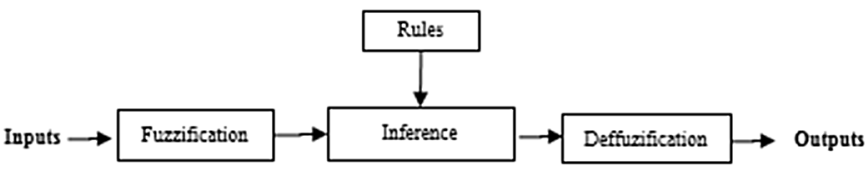

Fig. 9. Steps of fuzzy logic controller.

incorporates certain imperfections in everyday life, particularly while reasoning and deciding. The idea is to define a multivalued logic allowing to model these imperfections and to take into account the intermediate states between "all" and "nothing." In this perspective, a fuzzy controller does not require a system model to be set. The adjustment of algorithms is based on linguistic rules such as: as if ... Then ... In fact. These rules can be expressed using everyday language and the intuitive knowledge of a human operator.

In our application case, fuzzy logic is a method that will allow the reduction of error without the need for an exact knowledge of system mathematical model. The fuzzy controller is divided into three essential steps - fuzzification, inference, and defuzzification - as shown in Figure 9 [18-20].

- Fuzzification

Fuzzification consists on converting physical variables inputs into fuzzy sets, which is based on a membership degree for each input.

- Inference

This is where decisions are made. The inference uses rules for determining the output signal of the controller as a function of the input signals [21-23].

In these, rules intervene the operators AND and OR. The AND operator is applied inside a rule to link the variables. And the OR operator is applied outside the rules to link them. There are several methods of inference such as MAX-MIN method, MAX-PROD method, and SUMSPROD method. In our application case, the MAX-MIN inference method is used which realizes the AND operator for the minimum and the operator OR for the maximum.

For the conclusion, the operator THEN links the output variable with the degree of membership of the input variable.

- Defuzzification

This step allows to convert the fuzzy output variables at the end of inference step into adapted physical variables. There are several methods of defuzzification such as the maximum method, the weighted average method, and the centroid method (the so-called center of gravity). In this paper, the last method was used [24,25].

The input variables for the fuzzy controller are the power and the voltage variations.

$$
\begin{aligned}
& V(k)=V(k)-V(K-1) \\
& P(k)=P(k)-P(K-1) .
\end{aligned}
$$




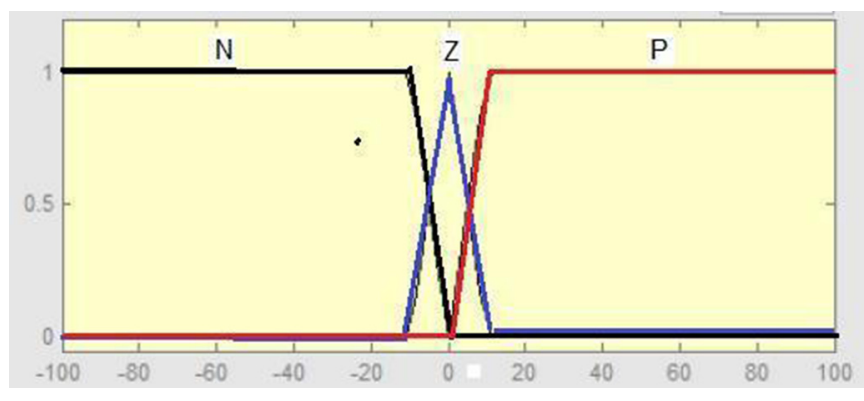

Fig. 10. Voltage variation membership function.

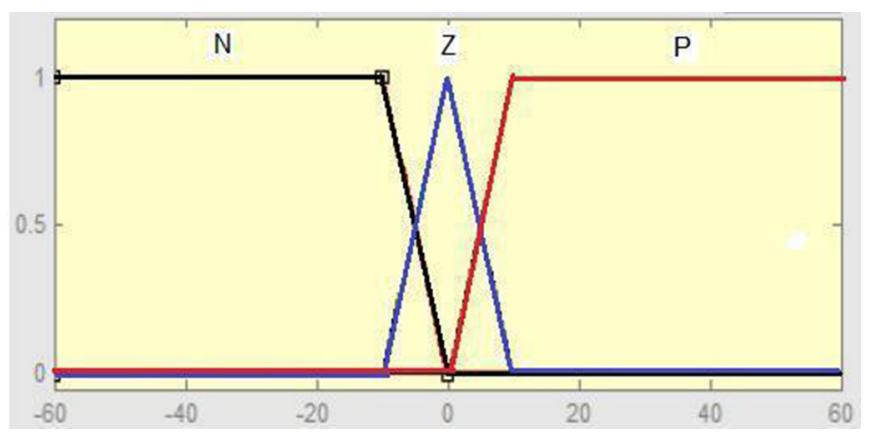

Fig. 11. Power variation membership function.

We consider three intervals for the inputs $V, P$, and the output $\mathrm{d} D$ :

- P: Positive;

- Z: Zero;

- N: Negative.

The membership functions of the output and the two inputs are shown in Figures 10-12.

The inference rules of this controller are derived from the classic $\mathrm{P} \& \mathrm{O}$ algorithm. Indeed, according to Figure 7, it can be deduced that:

- If $P$ is zero, so we are in PMP point and there is no variation of the duty cycle ( $\mathrm{d} D$ is zero).

- If $P$ and $\mathrm{V}$ have the same sign, so the duty cycle is increased ( $\mathrm{dD}$ is positive).

- If $P$ and $V$ have opposite sign, so the duty cycle is decreased ( $\mathrm{d} D$ is negative).

In the world of fuzzy logic, the following rules of inference can be stated:

- If $P$ is "P" and $V$ is "P" then $\mathrm{d} D$ is "N" (if $P$ is positive and $V$ is positive then $\mathrm{d} D$ is negative).

- If $P$ is " $\mathrm{P}$ " and $V$ is " $\mathrm{Z}$ " then $\mathrm{d} D$ is " $\mathrm{Z}$ " (if $P$ is positive and $V$ is zero then $\mathrm{d} D$ is zero).

- If $P$ is "P" and $V$ is "N" then $\mathrm{d} D$ is "P" (if $P$ is positive and $V$ is negative then $\mathrm{d} D$ is positive).

- If $P$ is "N" and $V$ is "P" then $\mathrm{d} D$ is "P" (if $P$ is negative and $V$ is positive then $\mathrm{d} D$ is positive).

- If $P$ is " $\mathrm{N}$ " and $V$ is " $Z$ " then $\mathrm{d} D$ is " $Z$ " (if $P$ is negative and $V$ is zero then $\mathrm{d} D$ is zero).

- If $P$ is "N" and $V$ is "N" then $\mathrm{d} D$ is "N" (if $P$ is negative and $V$ is negative then $\mathrm{d} D$ is negative).

- If $P$ is " $Z$ " and $V$ is "P" then $\mathrm{d} D$ is " $Z$ " (if $P$ is zero and $V$ is positive then $\mathrm{d} D$ is zero).

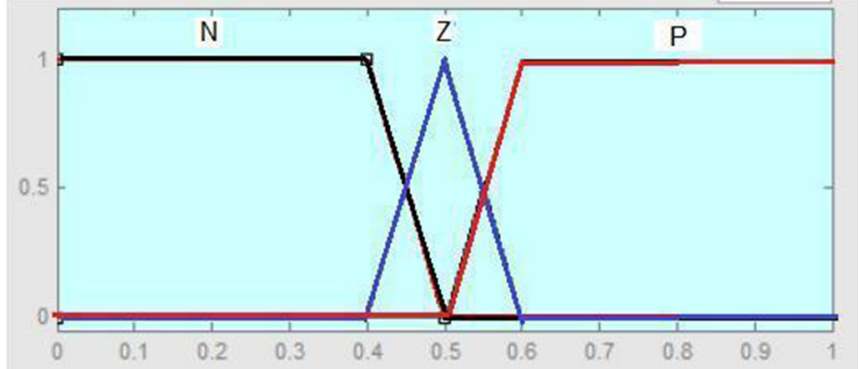

Fig. 12. Output membership function.

Table 2. Inference table.

\begin{tabular}{llll}
\hline Rule no. & $\Delta P$ & $\Delta P$ & $\mathrm{~d} D$ \\
\hline 1 & $\mathrm{P}$ & $\mathrm{P}$ & $\mathrm{N}$ \\
2 & $\mathrm{P}$ & $\mathrm{Z}$ & $\mathrm{Z}$ \\
3 & $\mathrm{P}$ & $\mathrm{N}$ & $\mathrm{P}$ \\
4 & $\mathrm{~N}$ & $\mathrm{P}$ & $\mathrm{P}$ \\
5 & $\mathrm{~N}$ & $\mathrm{Z}$ & $\mathrm{Z}$ \\
6 & $\mathrm{~N}$ & $\mathrm{~N}$ & $\mathrm{~N}$ \\
7 & $\mathrm{Z}$ & $\mathrm{P}$ & $\mathrm{Z}$ \\
8 & $\mathrm{Z}$ & $\mathrm{Z}$ & $\mathrm{Z}$ \\
9 & $\mathrm{Z}$ & $\mathrm{N}$ & $\mathrm{Z}$ \\
\hline
\end{tabular}

- If $P$ is "Z" and $V$ is "Z" then $\mathrm{d} D$ is " $Z$ " (if $P$ is zero and $V$ is zero then $\mathrm{d} D$ is zero).

- If $P$ is "Z" and $V$ is "N" then $\mathrm{d} D$ is " $Z$ " (if $P$ is zero and $V$ is negative then $\mathrm{d} D$ is zero).

These new fuzzy rules can be integrated in Table 2.

\section{Results and discussion}

\subsection{Current correction method}

The simulations for both classic and improved $\mathrm{P} \& \mathrm{O}$ algorithms are performed in the same conditions: a temperature of $25^{\circ} \mathrm{C}$ and a variable illumination.

The power behavior for these two cases is shown in Figure 13.

Figure 12 shows the power variation of the PV module depending on illumination variation. In fact, the improved algorithm has better response in the event of sudden insolation variation. Power loss in the case of $\mathrm{P} \& \mathrm{O}$ classic algorithm is $\mathrm{P} 1$. And, in the case of $\mathrm{P} \& \mathrm{O}$ optimized algorithm, the power loss is P2. By using optimization by current correction, we are able to gain in terms of $\mathrm{PV}$ panel power in case of illumination variation.

\subsection{Fuzzy logic method}

The simulations for both classic and fuzzy logic improved $\mathrm{P} \& \mathrm{O}$ algorithms is performed in a temperature of $25^{\circ} \mathrm{C}$ and an illumination of $1000 \mathrm{~W} / \mathrm{m}^{2}$ (Fig. 14). 

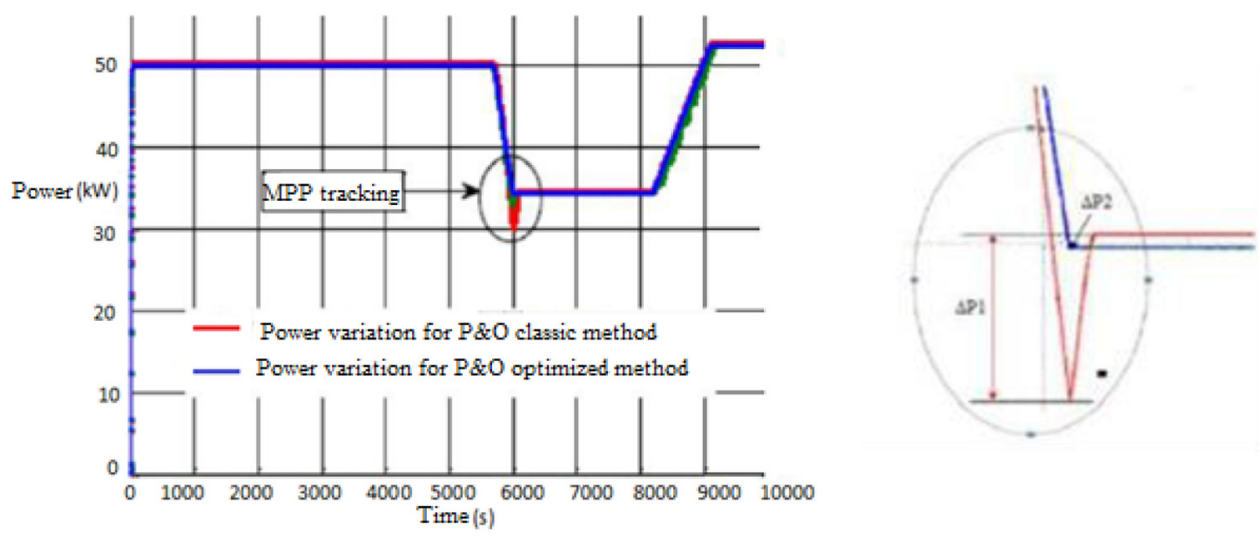

Fig. 13. Power variation and power loss for each algorithm.

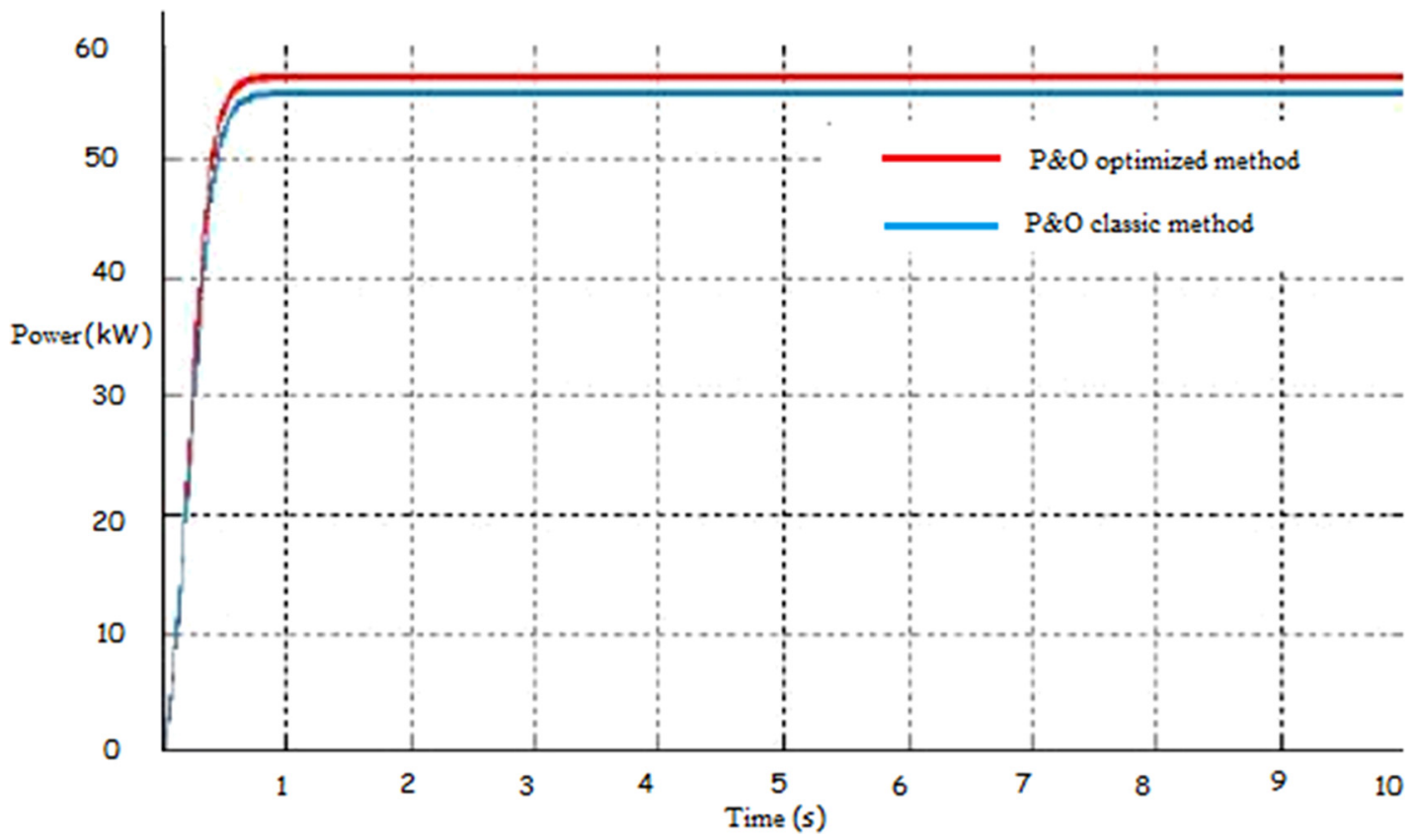

Fig. 14. Power curve for fixed climatic parameters.

Both power curves have the same shape especially in terms of speed and stability. However, the optimized method power curve is more precise. Next, we vary the illumination while keeping the temperature fixed at $25^{\circ} \mathrm{C}$ (Fig. 15).

The classic $\mathrm{P} \& \mathrm{O}$ algorithm curve was affected by the sudden change of illumination since the $\mathrm{P} \& \mathrm{O}$ improved algorithm behavior is more accurate.

\section{Conclusion}

PVG system based on a P\&O algorithm has been presented. The mathematical model was developed based on a one diode model and a boost convertor. This paper discussed two different optimization algorithms of the classic P\&O method: current correction and fuzzy logic to improve the efficiency of the system at different climate conditions especially illumination and temperature.

The simulated results show that both methods offer a remarkable improvement concerning power losses and precision. Comparison indicates that proposed models are effectives and accurate, and are less affected by sudden variation of climatic parameters.

From the simulation study, it has been found that fuzzy logic $\mathrm{P} \& \mathrm{O}$ optimized algorithm converges to the global optimum. 


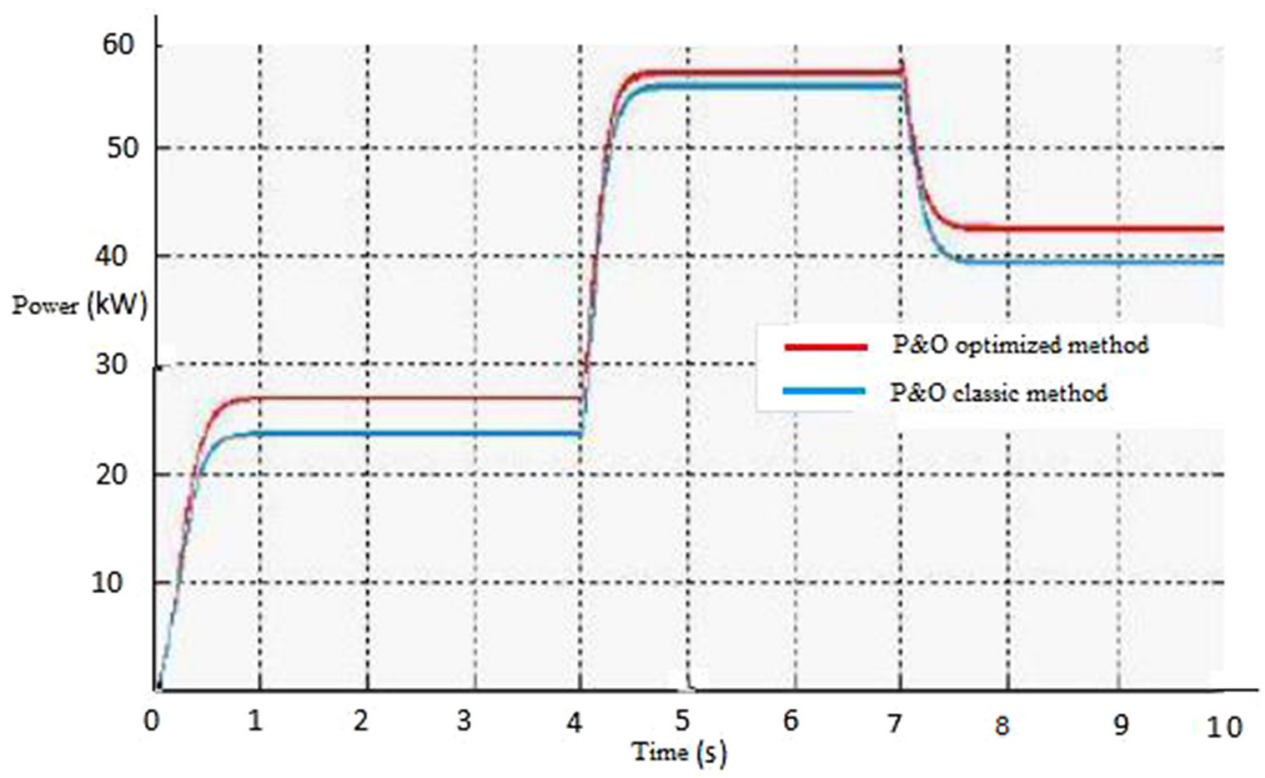

Fig. 15. Power curve for fixed temperature and variable illumination.

\section{Nomenclatures}

$\begin{array}{ll}R_{\mathrm{S}} & \begin{array}{l}\text { Line contact resistance } \\ R_{\mathrm{p}}, I_{\mathrm{R}}\end{array} \\ & \begin{array}{l}\text { Resistance and leakage current due to diode } \\ \text { and effects on the junction }\end{array} \\ I_{\mathrm{G}} & \begin{array}{l}\text { Current created by absorbed solar radiation. } \\ \text { It is practically worth the short circuit current } I_{\mathrm{cc}}\end{array} \\ \left(I_{\mathrm{PV}}, V_{\mathrm{PV}}\right) & \begin{array}{l}\text { Photovoltaic panel characteristics } \\ \text { Reserve saturation current }\end{array} \\ I_{0} & \text { Charge of electrons } \\ K & \text { Boltzmann constant } \\ T & \text { Temperature } \\ W & \text { Illumination } \\ a & \text { Duty cycle }\end{array}$

\section{References}

1. X. Liu, An improved perturbation and observation maximum power point tracking algorithm for PV panels, thesis presented for the Degree of Master of Applied Science, Concordia University, Montreal, Quebec, Canada, 2004

2. A. Pradeep Kumar Yadav, S. Thirumaliah, G. Haritha, Comparison of MPPT algorithms for DC-DC converters based PV systems, Int. J. Adv. Res. Electr. Eectron. Instrum. Eng. 1, 476 (2012)

3. K.H. Hussein, T. Hashino, Maximum photovoltaic power tracking: an algorithm for rapidly changing atmospheric conditions, IEE Proc. Gener. Transm. Distrib. 142, 59-64 (1995)

4. B. Subudhi, R. Pradhan. A comparative study on maximum power point tracking techniques for photovoltaic power systems, IEEE Trans. Sustain. Energy 4, 89-98 (2013)
5. S. Lyden, M.E. Haque, A. Gargoom, M. Negnevitsky, Review of maximum power point tracking approaches suitable for PV systems under partial shading conditions, in: Proceedings of the Australasian Universities Power Engineering Conference, Hobart, TAS, Australia, 2013, pp. $1-6$

6. K. Ishaque, Z. Salam, A review of maximum power point tracking techniques of PV system for uniform insolation and partial shading condition, Renew. Sustain. Energy Rev. 19, 475-488 (2013)

7. H.J. El-Khozondar, R.J. El-Khozondar, K. Matter, T. Suntio, A review study of photovoltaic array maximum power tracking algorithms, Renew. Wind Water Sol. 3, 3 (2016)

8. A. Soufyane Benyoucef, A. Chouder, K. Kara, S. Silvestre, O.A. Sahed, Artificial bee colony based algorithm for maximum power point tracking (MPPT) for PV systems operating under partial shaded conditions, Appl. Soft Comput. 32, 38-48 (2015)

9. A. Elnosh, V. Khadkikar, W. Xiao, J.L. Kirtely, An improved extremum-seeking based MPPT for grid-connected PV systems with partial shading, in: 2014 IEEE 23rd International Symposium on Industrial Electronics, Istanbul, Turkey, 2014, pp. 2548-2553

10. G.M. Masters, Renewable and efficient electric power systems (John Wiley \& Sons, Inc., Hoboken, NJ, 2004)

11. R.W. Erickson, DC-DC power converters, in: Wiley Encyclopedia of Electrical and Electronics Engineering (John Wiley \& Sons, NY, 2007)

12. M. Lokanadham, K. Vijaya Bhaskar, Incremental conductance based maximum power point tracking (MPPT) for photovoltaic system, Int. J. Eng. Res. Appl. 2, 1420-1424 (2012)

13. Salazar, F. Tadeo, C. Prada, L. Palacin, Simulation and control of a PV system connected to a low voltage network, Jornadas De Automática, 8-10 September 2010, Jaén, Spain 
14. N. Femia, G. Petrone, G. Spagnuolo, M. Vitelli, Optimization of perturb and observe maximum power point tracking method, IEEE Trans. Power Electron. 20, 963 (2005)

15. A. Chermitti, O. Boukli-Hacene, S. Mouhadjer, Design of a library of components for autonomous photovoltaic system under Matlab/Simulink, Int. J. Comput. Appl. 53, 13-19 (2012)

16. R.J. Wai, W.H. Wang, C.Y. Lin, High-performance standalone photovoltaic generation system, IEEE Trans. Ind. Electron. 55, 240-250 (2008)

17. C. Hua, J. Lin, An on-line MPPT algorithm for rapidly changing illuminations of solar arrays, Renew. Energy 28, 997-1157 (2003)

18. A. Harrag, S. Messalti, How fuzzy logic can improve PEM fuel cell MPPT performances?, Int. J. Hydrogen Energy 43, 537 (2017)

19. A. Harrag, H. Bahri, Novel neural network IC-based variable step size fuel cell MPPT controller: performance, efficiency and lifetime improvement, Int. J. Hydrogen Energy 42, $3549 \mathrm{e} 63$ (2017)
20. N.H. Saad, A.A. El-Sattar, A.M. Mansour, Adaptive neural controller for maximum power point tracking of ten parameter fuel cell model, J. Electr. Eng. 13, 1e7 (2013)

21. R.W. Erickson, Fundamentals of power electronics (Chapman \& Hall, New York, 1997)

22. J. Prakash, S.K. Sahoo, S.P. Karthikeyan, I.J. Raglend, Design of PSO-fuzzy MPPT controller for photovoltaic application power electronicsand renewable energy systems (Springer, India, 2015), pp. 1339-1348

23. K. Premkumar, B.V. Manikandan, Adaptive neuro-fuzzy inference system based speed controller for brushless DC motor, Neurocomputing 138, 260-270 (2014)

24. A. Chaouachi, R.M. Kamel, K. Nagasaka, A novel multimodel neuro-fuzzy-based MPPT for three-phase gridconnected photovoltaic system, Sol. Energy 84, 2219-2229 (2010)

25. C. Larbes, S.A. Cheikh, T. Obeidi, A. Zerguerras, Genetic algorithms optimized fuzzy logic control for the maximum power point tracking in photovoltaic system, Renew. Energy 34, 2093-2100 (2009)

Cite this article as: Meriem Ourahou, Wiam Ayrir, Ali Haddi, Current correction and fuzzy logic optimizations of Perturb \& Observe MPPT technique in photovoltaic panel, Int. J. Simul. Multidisci. Des. Optim. 10, A6 (2019) 